\title{
Article \\ Effect of the Metal Transfer Mode on the Symmetry of Bead Geometry in WAAM Aluminum
}

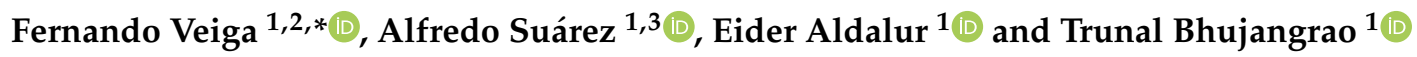 \\ 1 TECNALIA, Basque Research and Technology Alliance (BRTA), Parque Científico, Parque Científico y \\ Tecnológico de Gipuzkoa, 20009 Donostia-San Sebastián, Spain; alfredo.suarez@tecnalia.com (A.S.); \\ eider.aldalur@tecnalia.com (E.A.); trunal.bhujangrao@tecnalia.com (T.B.) \\ 2 Department of Engineering, Public University of Navarre, Los Pinos Building, Campus Arrosadía, \\ 31006 Pamplona, Spain \\ 3 ADDILAN Fabricación Aditiva S.L., Eguzkitza 1, 48200 Durango, Spain \\ * Correspondence: fernando.veiga@tecnalia.com; Tel.: +34-9431-05115
}

Citation: Veiga, F.; Suárez, A.; Aldalur, E.; Bhujangrao, T. Effect of the Metal Transfer Mode on the Symmetry of Bead Geometry in WAAM Aluminum. Symmetry 2021, 13, 1245. https://doi.org/10.3390/ sym13071245

Academic Editor: Miroslav Milet in

Received: 16 May 2021

Accepted: 9 July 2021

Published: 10 July 2021

Publisher's Note: MDPI stays neutral with regard to jurisdictional claims in published maps and institutional affiliations.

Copyright: () 2021 by the authors. Licensee MDPI, Basel, Switzerland. This article is an open access article distributed under the terms and conditions of the Creative Commons Attribution (CC BY) license (https:// creativecommons.org/licenses/by/ $4.0 /)$.

\begin{abstract}
The symmetrical nature in the case of wall fabrication by wire arc additive manufacturing (WAAM) has been observed in the literature, but it has not been studied as a source of knowledge. This paper focuses on the comparative study of three drop transfer methods employing Gas Metal Arc Welding (GMAW) technology, one of the most reported for the manufacture of aluminum alloys. The transfer modes studied are the well-known pulsed GMAW, cold arc, and the newer pulsed AC. The novelty of the last transfer mode is the reversal of the polarity during the preparation phase of the substance for droplet deposition. This study compares the symmetry of zero beads to determine the best parameters and transfer modes for wire arc additive manufacturing of 5 series aluminum. The pulsed transfer modes show values of 0.6 for symmetry ratio, which makes them more interesting strategies than cold arc with a symmetry ratio of 0.5 . Furthermore, the methodology proposed in this study can be extrapolated to other materials manufactured with this technology.
\end{abstract}

Keywords: direct energy deposition; wall geometry; additive manufacturing monitoring

\section{Introduction}

Additive manufacturing is one of the most rapidly growing topics in the manufacturing and engineering world today [1]. It consists of adding material layer by layer to manufacture bodies in three dimensions, which allows reducing the amount of material used [2].

WAAM technology uses a wire of metallic material as the material and arc welding as the heat source. The head provides heat to the wire and melts it, depositing it on a base (if it is the first layer) or on the previously deposited, already cooled layer. The use of WAAM technologies has been progressively improving, especially in the last 10 years [3]. In the past, it has had other designations, such as Solid Freeform Fabrication (SFF), Shape Metal Deposition (SMD), and even 3D Welding [4].

The main advantages of WAAM technology over traditional manufacturing processes have been listed by S. Williams et al. [5] and are presented in terms of open architecture, part size, deposition rate, and material cost.

There are three different types of WAAM processes, depending on the heat source used: GMAW (Gas Metal Arc Welding), GTAW (Gas Tungsten Arc Welding), and PAW (Plasma Arc Welding). The use of one type or another directly influences the processing conditions and the production rate [3]. So far, the GTAW and PAW processes have proven to be the most reliable for WAAM with less distortion, excessive heating, and porosity problems than GMAW. However, in these two technologies, the wire is not fed coaxially, which leads to introducing variations in the process when the material feed direction is changed, resulting in excessive sensitivity to arc length. Many robotic systems require a 
rotating axis to guide the wire, which limits their applicability [6]. However, in order to establish GMAW as an interesting alternative for the above technologies, the necessary initial objective is the detailed study of the strategies of torch movement [7] and the modes of metal transfer [8], to identify the most interesting types in each application [9], including the most recent modes, such as pulsed AC, which is discussed in this paper.

A correct selection of the deposition parameters to obtain a correct bead is critical. Multiple process-monitoring techniques [10] have been presented. Along these lines, the geometry of the melt pool has received great attention [11]. The monitoring of the bead geometry by vision techniques $[12,13]$ has also been studied.

The geometry of the bead is one of the aspects that have received the most attention from the scientific community, since the first articles [14]. Its importance lies in the ability to fill the joint in welding and is more relevant in its application to WAAM since it determines the external geometry of the piece [15]. If this technology is to be an alternative to the Near Net Shape (NNS), a correct shape and dimension of the bead are key. Most of the articles focus on the statistical modeling of the width and height of the bead, either by statistical models (regression [16], neural networks [17]), analytical models [18], or finite element models [19], although zero-bead analysis can be considered suitable for processes such as welding, cladding, or WAAM. In this paper, it is focused on the study of WAAM because the material is deposited on the substrate directly, without a joint preparation. The analysis of the first bead for the determination of the correct parameters of wall or part fabrication by WAAM is widely spread [20-27].

In an attempt to provide a summary of the scientific community's interest in bead geometry analysis in wire arc additive manufacturing processes, Table 1 summarizes some of the work carried out in recent years in this field. Bead analysis allows this technology to be an alternative for the manufacture of near-net-shape (NNS) parts.

Table 1. Summary of recent contributions concerning the analysis of bead geometry.

\begin{tabular}{|c|c|c|c|}
\hline Authors & Measured Entity & Measurement Methodology & Geometric Determination Procedure \\
\hline Ding et al. [20] & $\begin{array}{l}\text { Overlapping distance (OD) and } \\
\text { bead height }(\mathrm{BH})\end{array}$ & 3D laser scanner & $\begin{array}{l}\text { The raw data of weld bead profile was } \\
\text { processed to obtain the geometrical } \\
\text { features OD and BH. A data-processing } \\
\text { algorithm was proposed with the } \\
\text { following steps: (i) denoising filter of the } \\
\text { signal, (ii) extraction of the bead profile, } \\
\text { (iii) curve fitting of the profile, and (iv) OD } \\
\text { and BH calculation }\end{array}$ \\
\hline Karmuhilan et al. [21] & Bead height and width & $\begin{array}{l}\text { Coordinate measuring machine } \\
\text { (CMM) }\end{array}$ & $\begin{array}{l}\text { Welding process parameters were } \\
\text { processed to control the bead geometry } \\
\text { through an artificial neural network } \\
\text { (ANN) model of bead parameters }\end{array}$ \\
\hline Venkatarao [22] & $\begin{array}{c}\text { Depth of weld bead (DWB), width } \\
\text { of weld bead (WWB), height of } \\
\text { the weld bead (HWB), and width } \\
\text { of molten pool (WWP) }\end{array}$ & $\begin{array}{l}\text { Cut across the weld beads to } \\
\text { measure weld bead geometry } \\
\text { with a microscope }\end{array}$ & $\begin{array}{l}\text { A teaching-learning-based optimization } \\
\text { technique was used for optimizing weld } \\
\text { bead geometry. Some insights of the work } \\
\text { presented suggest that bead profile has a } \\
\text { symmetrical lookalike and it is modeled as } \\
\text { a parabolic function: } \\
y=a x^{2}+h \\
\text { Additionally, finite element modeling was } \\
\text { used for the molten pool geometry } \\
\text { estimation }\end{array}$ \\
\hline Dinovitzer et al. [23] & $\begin{array}{l}\text { Weld bead height, width, wetting } \\
\text { angle, melt-through depth, and } \\
\text { bead roughness }\end{array}$ & $\begin{array}{l}\text { SEM scanning electron } \\
\text { microscope (SEM) and } \\
\text { profilometer }\end{array}$ & $\begin{array}{l}\text { The welding parameters: travel speed, } \\
\text { wire feed speed, current, and argon flow } \\
\text { rate, were used in the Taguchi method and } \\
\text { ANOVA to determine the effects on } \\
\text { geometry. } \\
\text { To determine the variability of the bead, } \\
\text { surface roughness was measured. If there } \\
\text { are no variations in height or undulations, } \\
\text { the bead is considered to have a relatively } \\
\text { constant geometrical accuracy }\end{array}$ \\
\hline
\end{tabular}


Table 1. Cont.

\begin{tabular}{|c|c|c|c|}
\hline Authors & Measured Entity & Measurement Methodology & $\begin{array}{c}\text { Geometric Determination } \\
\text { Procedure }\end{array}$ \\
\hline Tang et al. [24] & $\begin{array}{l}\text { Arc striking (AS) and arc } \\
\text { extinguishing (AE) area }\end{array}$ & $\begin{array}{c}\text { Infrared camera and arial } \\
\text { topography } \\
\text { measurement sensor }\end{array}$ & $\begin{array}{l}\text { This paper presents a detailed study } \\
\text { of the geometry in the initial and final } \\
\text { zone of the bead. To avoid } \\
\text { geometrical errors in the area AE, a } \\
\text { burning-back method was } \\
\text { investigated }\end{array}$ \\
\hline Li et al. [25] & $\begin{array}{c}\text { Bead width }(\mathrm{W}) \text { and bead } \\
\text { height }(\mathrm{H})\end{array}$ & Laser displacement scanner & $\begin{array}{l}\text { They introduce a geometric term to } \\
\text { calculate the ratio between width and } \\
\text { height (RWTH). This RWTH ratio is } \\
\text { indicative of the variation of the } \\
\text { chord geometry since theoretically } \\
\text { the cross-sectional area is a constant } \\
\text { value }\end{array}$ \\
\hline $\begin{array}{c}\text { Sarathchandra et al. } \\
{[26]}\end{array}$ & $\begin{array}{l}\text { Bead width, bead height, } \\
\text { penetration and dilution }\end{array}$ & $\begin{array}{l}\text { 3D optical microscope and } \\
\text { treatment using open-source } \\
\text { software ImageJ }\end{array}$ & $\begin{array}{l}\text { Input current (I), standoff distance } \\
\text { (D), and welding speed (S) are taken } \\
\text { as input parameters for the multiple } \\
\text { regression models to ensure the bead } \\
\text { quality }\end{array}$ \\
\hline Wang et al. [27] & $\begin{array}{l}\text { Track width }(\mathrm{w}) \text {, layer height } \\
\qquad(\mathrm{h}), \text { penetration }(\mathrm{p}), \\
\text { accumulated area }(\mathrm{A} 2), \\
\text { penetration area }(\mathrm{A} 1), \text { aspect } \\
\text { ratio }(\mathrm{B}=\mathrm{w} / \mathrm{h}) \text {, and dilution } \\
\text { ratio }(\mathrm{D}=\mathrm{A} 1 /(\mathrm{A} 1+\mathrm{A} 2))\end{array}$ & $\begin{array}{l}\text { Laser profile scanner and } \\
\text { microscope image }\end{array}$ & $\begin{array}{l}\text { The Box-Behnken design response } \\
\text { surface optimization method was } \\
\text { adopted to predict the geometrical } \\
\text { parameters of the bead using the } \\
\text { process parameters in cold metal } \\
\text { transfer arc additive manufacturing } \\
\text { (CMT-WAAW) in aluminum }\end{array}$ \\
\hline
\end{tabular}

Although these analyses are widely used, no work to date has evaluated bead symmetry as a bead quality parameter. The objective of this work is to compare three of the most widely used metal transfer modes, namely two sprayed pulsed GMAW and pulsed AC and cold arc. To this end, the novelty presented by this paper is the comparison of the symmetry of the bead produced using image processing.

\section{Materials and Methods}

This section describes on the one hand the material resources and the experimental design used to compare the transfer modes. Lastly, the methods used for the analysis of the images and the study of the symmetry are defined.

\subsection{Experimental Set-Up}

The material used in this paper is a magnesium-aluminum filler metal, the alloy $\mathrm{Al}$ 5356 that has levels of $\mathrm{Mg} 4.8$, Ti 0.081, and Mn 0.16, together with the addition of chromium $\mathrm{Cr} 0.12$ and a slight reduction of silicon 0.05 . These changes together serve to increase its resistance to corrosion and make it the best aluminum for use in marine applications. It is a widely used filler metal for its affinity with multiple other aluminum alloys, generally with argon as a protective gas. Al5356 has a melting point of 570 to $635^{\circ} \mathrm{C}$. The wire used in this work was a $1.2 \mathrm{~mm}$ diameter EN ISO 18273:S Al5356 commercial wire with aluminum 5356 plates of $15 \mathrm{~mm}$ thickness as the substrate. The GMAW-WAAM technology was used. The machine used for the tests was an Addilan v0.1 (Durango, Spain) equipped with Alpha Q 552 pulse-welding equipment from the EWM brand (Mündersbach, Germany). This machine equips a turntable and a controllable environment.

The torch, with an inclination angle of $90^{\circ}$ concerning the substrate, used a $20 \mathrm{~mm}$ diameter nozzle to manufacture the bead. A mixture of $80 \%$ Ar and $20 \% \mathrm{CO}_{2}$ was used as shielding gas at a flow rate of $18 \mathrm{~L} / \mathrm{min}$. A $17 \mathrm{~mm}$ stick-out was used. Figure 1 shows 
the arrangement of the components in the additive manufacturing; the axes on which the symmetry of the zero bead is analyzed are described.

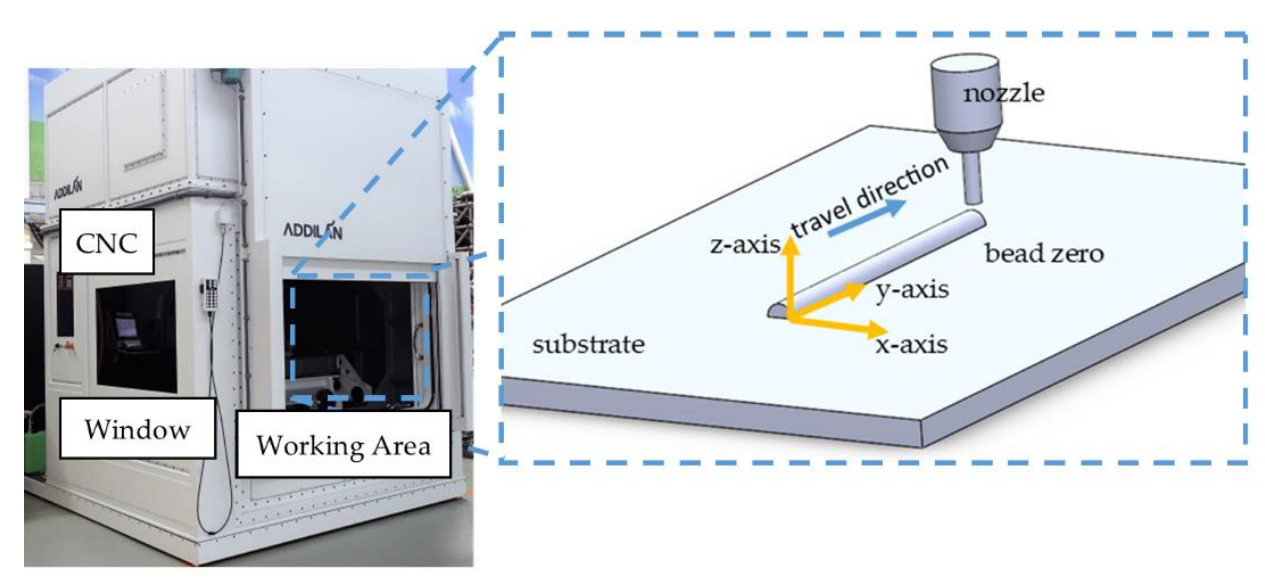

Figure 1. Experimental set-up: schematic diagram of the axes in the analysis of the symmetry of the zero bead.

The three modes of pulsed GMAW, cold arc, and pulsed AC transfer are compared at 2 wire speeds, 4 and $8 \mathrm{~m} / \mathrm{min}$, with 3 ratios, which is considered as the relationship between the travel speed and the wire feed; welding conditions are better described in [28]. Table 2 summarizes the chosen parameters.

Table 2. Design of experiments for comparison of metal transfer modes.

\begin{tabular}{ccccc}
\hline Test Run\# & $\begin{array}{c}\text { Wire Feed } \\
(\mathbf{m} / \mathbf{m i n})\end{array}$ & $\begin{array}{c}\text { Traverse Speed } \\
(\mathbf{c m} / \mathbf{m i n})\end{array}$ & $\begin{array}{c}\text { Deposition Rate } \\
(\mathbf{k g} / \mathbf{h})\end{array}$ & Ratio \\
\hline $\mathbf{1}$ & 4 & 100 & 0.72 & 4 \\
$\mathbf{2}$ & 4 & 57 & 0.72 & 7 \\
$\mathbf{3}$ & 4 & 33 & 0.72 & 12 \\
$\mathbf{4}$ & 8 & 200 & 1.44 & 4 \\
$\mathbf{5}$ & 8 & 114 & 1.44 & 7 \\
$\mathbf{6}$ & 8 & 65 & 1.44 & 12 \\
\hline
\end{tabular}

\subsection{Metal Transfer Modes}

The metal transfer method is critical when making parts by direct energy deposition. This affects the metallographic characteristics of the wall and distortions of the final piece due to the heat generated and the amount of material deposited instantaneously. Likewise, it also affects the external geometry of the bead in each of the layers for which the part is sliced. This section briefly describes the generating wave of the drop in each of these three modes.

There are three main processes of metal transfer modes, as reported in the review [29]: spray transfer, globular transfer, and short-circuit transfer. Over the past few decades, welding sources with high-frequency control strategies have been used to control this metal transfer. These control strategies imposed by each synergistic work mode define the waveform of the current signal applied to the load at the welding source. The current waveform can influence the dynamics of the weld pool and the heat input, which are key factors in achieving specific microstructures and potential metallurgical defects.

These modes are limited to specific deposition ranges that the welding machine manufacturer specifies as deposition rate limits for each mode. For example, the pulsed GMAW mode can transfer one drop per pulse in a controlled manner with high deposition rates, as described in [28]. The power transferred to the process in the pulsed GMAW mode is lower than that of the non-pulsed GMAW mode and, therefore, the heat input is also lower [30]. In a study of pulsed arc and non-pulsed arc WAAM processes, the authors in [31] concluded that the manufacturing efficiency was higher and the process control was 
greater in the pulsed arc WAAM processes. On the other hand, the short-circuiting metal transfer mode controlled by the cold arc mode achieves low deposition rates, and reduces the overall heat input during deposition compared to the conventional GMAW working modes [32,33]. Finally, the new pulsed AC mode, which uses the variable polarity of the current signal, achieves high deposition rates. Variable polarity current signals are not new, but the use of these types of signals in high-deposition-rate processes is a novelty $[34,35]$. Different deposition rates influence the parameters of the welding process and, ultimately, the material properties and melt geometry. Therefore, it is important to choose the right mode during the manufacturing process.

\subsubsection{Pulsed GMAW}

Pulsed GMAW is one of the transfer methods based on the spraying of metallic drops, based on the modification of current, the voltage from the generation phase. This current is supplied by the heat generator in the form of a wave train. The droplet occurs mainly during the peak current phase and is shed in the phase where the current is lowered. This valley current maintains the arc while maintaining minimal heat transfer to the substrate. This wave train has a frequency between 30 and $200 \mathrm{~Hz}$, depending on the desired deposition ratio. Therefore, the wave frequency leads to the deposition of a greater quantity of material, ensuring a drop of the same volume at different ratios. In Figure 2, we can see the form of two waves, in which the peak and valley phase of the signal is observed.

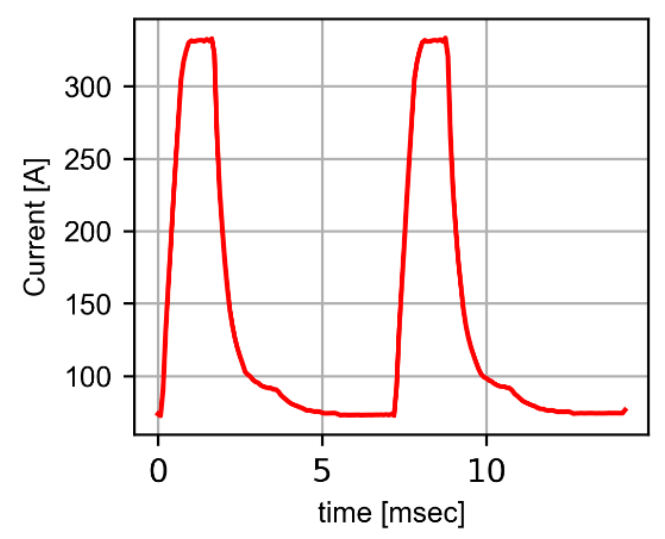

Figure 2. The shape of the current in pulsed GMAW transfer mode for two complete waves.

A synergistic GMAW pulsed process was used in this paper. In this process, the generator automatically adjusts the current and voltage parameters to the wire speed necessary to produce material at the commanded deposition ratio. It is the most widespread method today because it allows a faster adaptation and usability by the operator.

\subsubsection{Cold Arc}

The principle of metal deposition in cold arc is based on causing a controlled shortcircuit to deposit the drop. It is based on carrying out a short-circuit and re-ignition of the arc in a controlled process with a short reaction time. During the material melting process, the electrode (wire) is brought closer, keeping the current and voltage theoretically constant. It is observed that the material deposition does not occur at a constant frequency, being a somewhat more erratic deposition than in the case of the metal projection of the processes (pulsed AC and pulsed GMAW) in which the deposition is at a more constant frequency. In Figure 3, two complete waves are observed in which the different phases of controlled current are observed. 


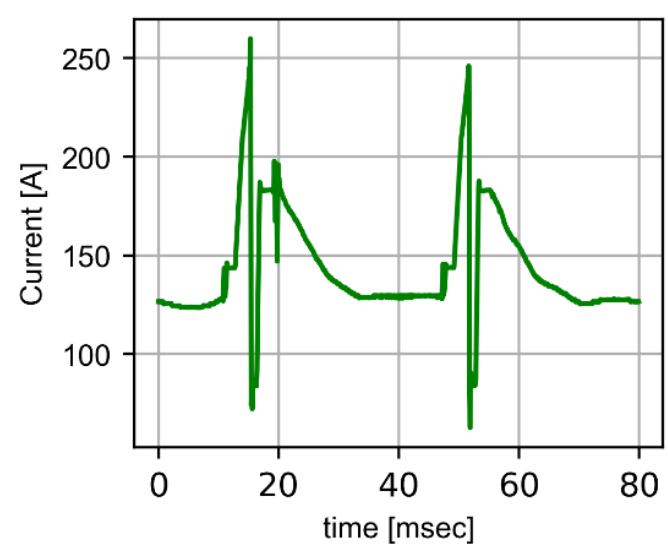

Figure 3. The shape of the current in cold arc transfer mode for two complete waves.

\subsubsection{Pulsed AC}

In pulsed $\mathrm{AC}$ mode, a current signal with variable polarity at a high deposition ratio is used; this is the main novelty of the method, which derives from the previous cold metal transfer (CMT) modes at low deposition with advanced pulse [35]. This process occurs at a frequency between 40 and $200 \mathrm{~Hz}$. In Figure 4, the phases of the current wave are seen with an ascending ramp to a stretch of constant current, then there is a descent to a base current. Finally, the polarity is reversed once the drop is detached, until the next cycle.

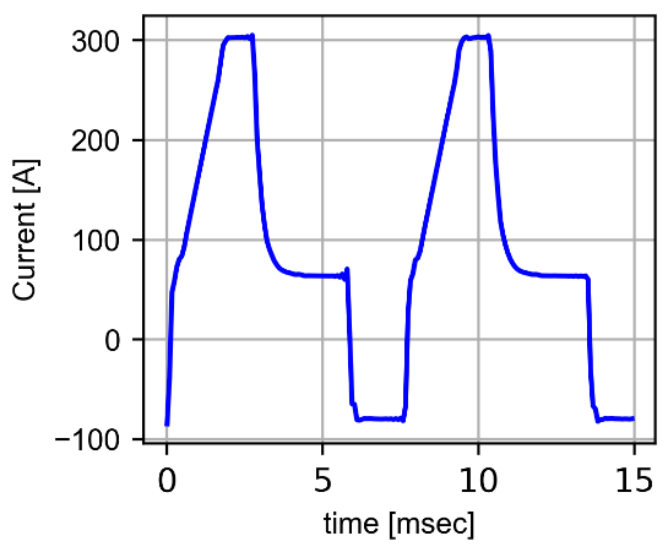

Figure 4. The shape of the current in pulsed AC transfer mode for two complete waves.

\subsection{Image Processing}

The first treatment on the images obtained from the microscope was carried out to determine the center line in which to compare the symmetry of the bead both in its transverse and longitudinal section. The walls and zero-layer weld beads were first crosssectioned in the middle portion and mechanically polished with Barker's electrolytic, and etching was performed to reveal the grain, applying $14 \mathrm{~V}$ for $120 \mathrm{~s}$. After preparation, each sample was observed with an optical microscope (Eclipse MA200 Nikon). The inverse blur filter on a low-noise image was applied in order to shape the image. Figure 5 shows the sequence followed for image processing, similar to that shown by [36]. 
(a)

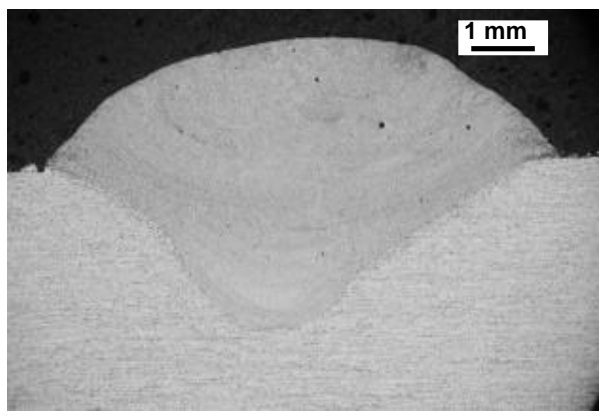

(c)

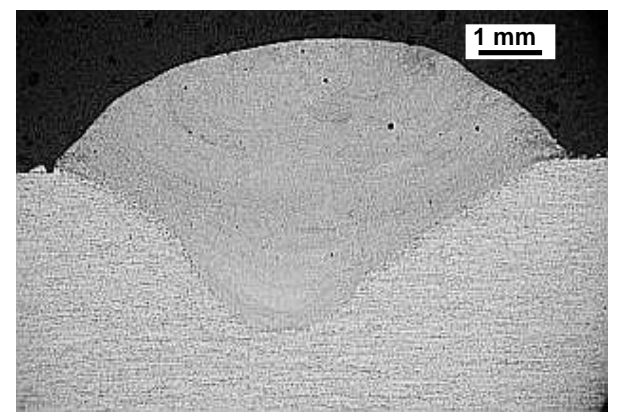

(b)

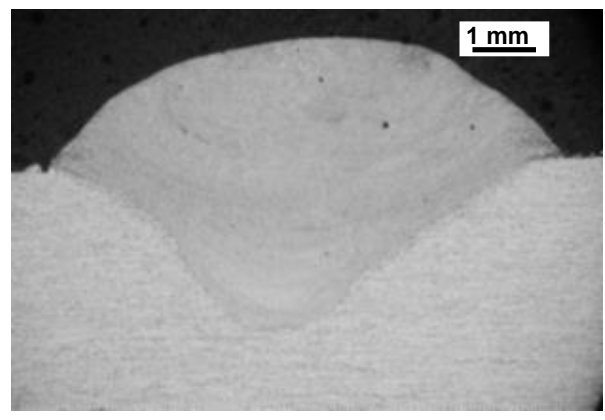

(d)

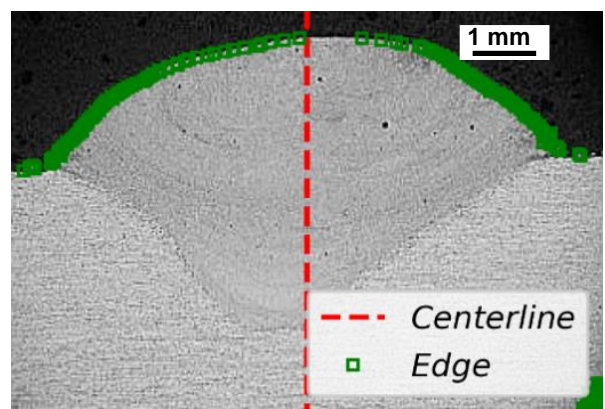

Figure 5. Transverse plane image of the bead: (a) original macroscope image, (b) blurred image, (c) sharpened image, and (d) edge-centerline determination.

The original bead image in the transverse plane is the starting point for the image processing, Figure 5a; this image, processed by employing a Gaussian filter, allows us to obtain both the blurred image in Figure $5 b$, and by applying the inverse filter, the sharpened image in Figure $5 \mathrm{c}$. This sharpened image allows us to determine the edges of the bead and position the centerline that will serve as the zero line on the $x$-axis for the calculation of symmetry in the transverse bead. Figure $5 \mathrm{~d}$ shows how this solution provides a good resolution of the centerline. The original image is the one that was used to study symmetry.

The sequence shows how the central line of the cross image is obtained. A filtering was carried out based on the Gaussian filter and the edges of the bead were obtained with the sharpest image. These edges define the center. Once the centerline was obtained, the symmetry calculation was performed on the original image. The original image had $312 \times 212$ pixels, and the pixel size corresponded to 26 square microns of real area once the scale was applied.

\subsection{Symmetry Analysis}

For the analysis of the symmetry in the bead image in layer 0 , an approach similar to that used by Zielke et al. [37] was applied to the non-industrial images. The function $y=f(x)$ was taken, where $\mathrm{y}$ is the intensity of the pixel in the gray color scale. The $\mathrm{x}$ corresponds to the position for the center line. Therefore, $y=f(x)$ gives the intensity to the right of the central line, and $y=f(-x)$ to the left. Figure 6 shows the intensity value on the grayscale for a given height $(\mathrm{z}=3)$. 


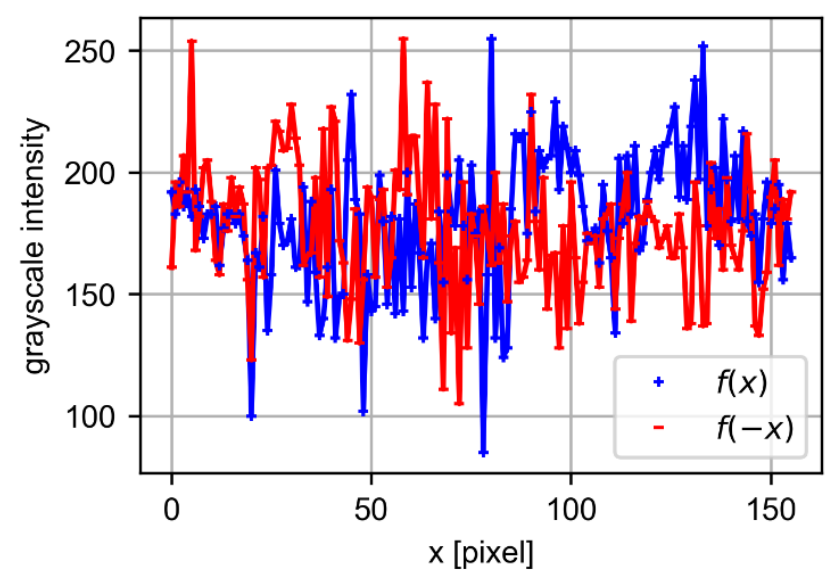

Figure 6. $f(x), f(-x)$ intensity functions on the gray scale evaluated at a given height $(\mathrm{z}=3)$.

The bead image would be perfectly symmetrical when $f(x)=f(-x)$. Therefore, for the quantification, the symmetric and antisymmetric functions are defined through the $z$ axis in Figure 1 as:

$$
\begin{aligned}
f_{s}(z) & =\frac{\overline{(f(x)+f(-x))}}{2} \\
f_{a s}(z) & =\frac{\overline{(f(x)-f(-x))}}{2}
\end{aligned}
$$

Figure 7 shows the evolution along the $z$-axis of the bead symmetry at each height as the mean of the difference of the intensities on the grayscale.

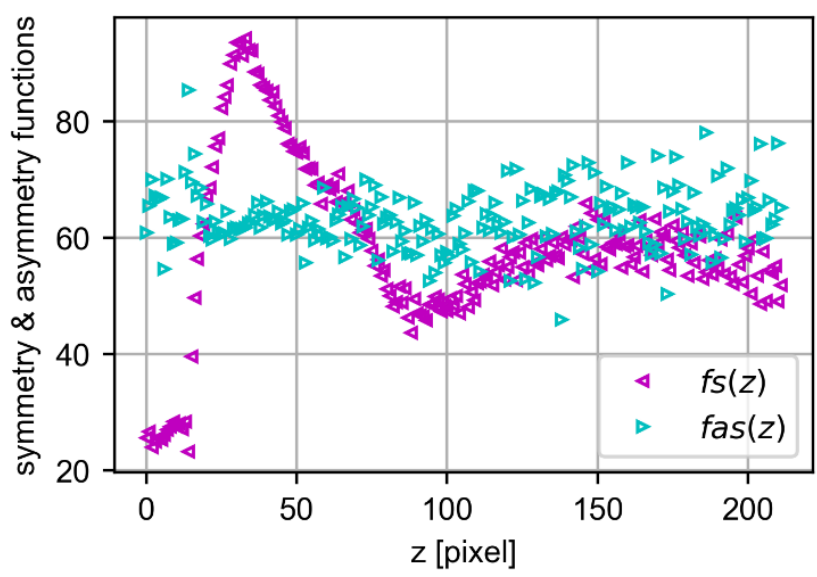

Figure 7. $f_{s}(z), f_{a s}(\mathbf{z})$ symmetrical and antisymmetrical functions on the grayscale evaluated along the $z$-axis.

From these two functions, a ratio is established that takes values continuous between $(0,1)$. The symmetric ratio takes a maximum value of 1 when the symmetry is pure and 0 when it is pure asymmetric. The correlation coefficient is between $(-1,1)$. These ratios can be expressed as:

$$
\begin{gathered}
S=\frac{\left\|f_{s}(z)\right\|^{2}}{\|f(z)\|^{2}}=\frac{\left\|f_{s}(z)\right\|^{2}}{\left\|f_{s}(z)\right\|^{2}+\left\|f_{a s}(z)\right\|^{2}} \\
C=\frac{\left\|f_{s}(z)\right\|^{2}-\left\|f_{a s}(z)\right\|^{2}}{\left\|f_{s}(z)\right\|^{2}+\left\|f_{a s}(z)\right\|^{2}} \\
C=2 \cdot S-1
\end{gathered}
$$


Figure 8 shows the evolution along the $z$-axis of the bead symmetry ratio at each height of the $\mathrm{z}$ bead. It can be seen how in the initial section the symmetry is less than in the area where the same bead is located, obtaining its highest values in the dilution zone that shows symmetry results higher than 0.6 . The total symmetry index of the bead image is considered the mean of all these values, which in this case is 0.45 , with a median value of 0.44 , and a standard deviation of 0.12 .

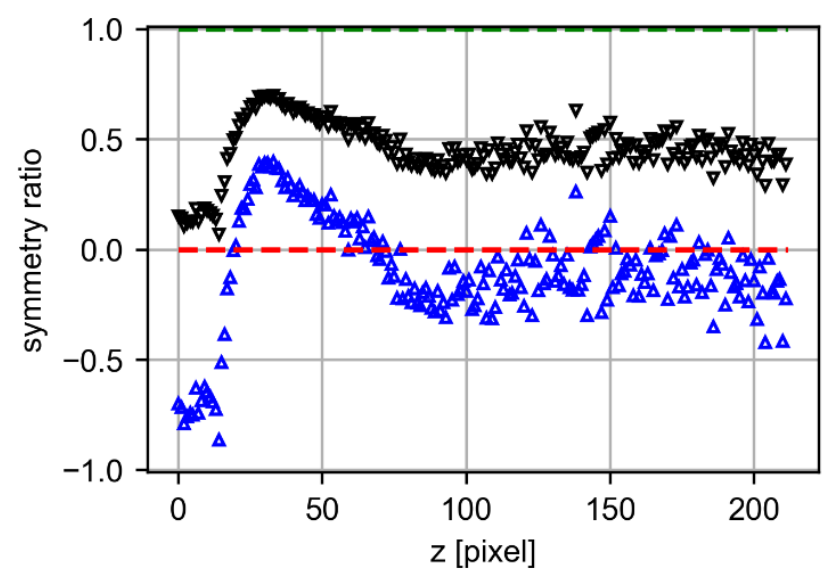

$$
\begin{array}{cl}
\Delta & C[f(x)] \\
\nabla & S[f(x)] \\
--- & \text { pure - antisymmetry } \\
--- & \text { pure - symmetry }
\end{array}
$$

Figure 8. Result of symmetric ratio (S) and correlation coefficient (C) evolution in the pulsed GMAW test \#5 along the $z$-axis.

\section{Results}

The results are divided between the analysis of the images in the zero bead in the longitudinal direction and the transverse direction obtained from the three different modes. The longitudinal analysis already discards some of the sets of parameters that do not produce a continuous bead so they could not be used for the manufacture of walls with GMAW technology.

\subsection{Zero Bead Symmetry Evaluation on the Longitudinal Axis}

The first analysis focuses on the longitudinal image of the beads. This analysis makes it possible to rule out some depositional conditions. Table 3 shows the set of results obtained. At a first glance cold-Arc for low deposition rates is not suitable. 
Table 3. Mono-layer weld beads' surface appearance, manufactured under three different working modes in the longitudinal view.

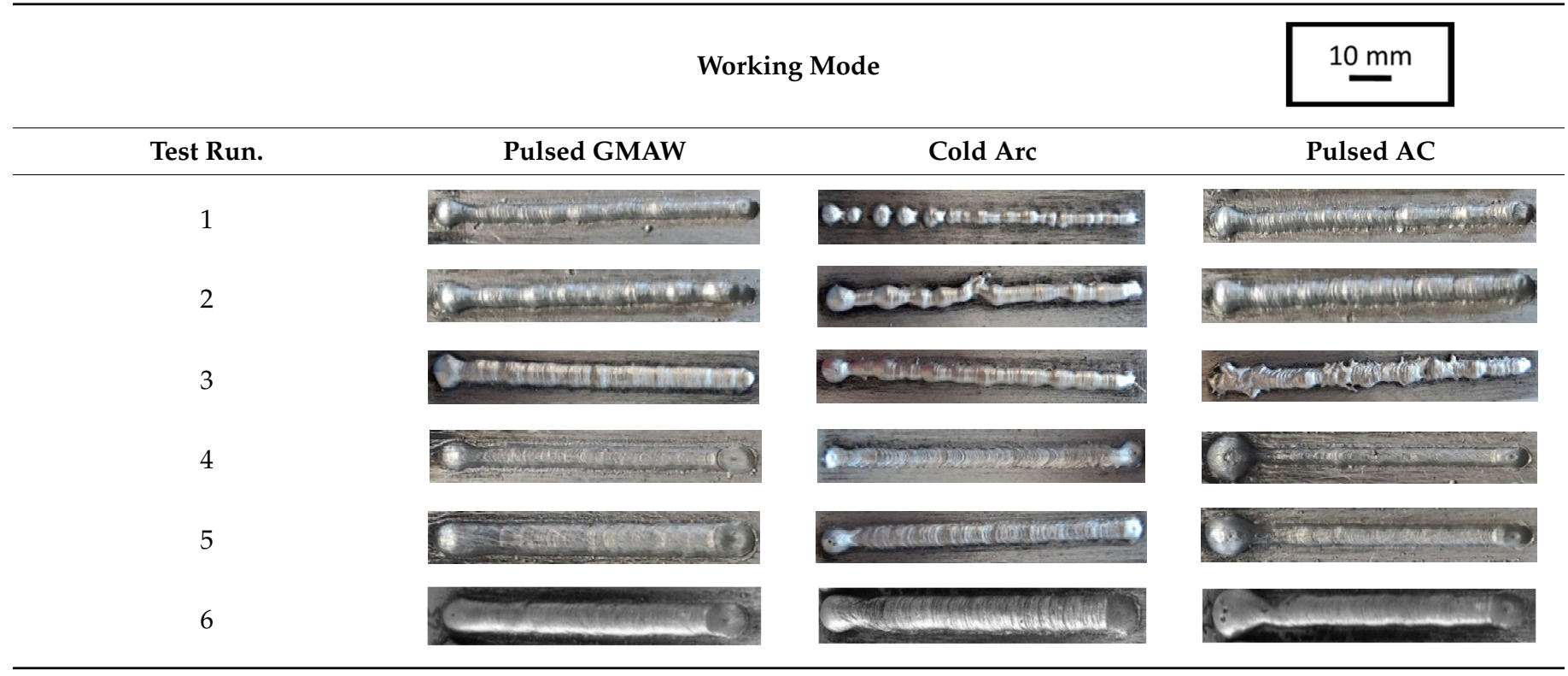

For the calculation of the symmetry in the advance, longitudinal direction, a moving window was used in the calculation of symmetry. The way to proceed is starting from the image of the bead in the xy plane (Figure 9a); the beginnings (Figure 9b) and ends (Figure 9c) of the deposition are discarded to avoid abnormality at the start and end of the weld bead [38], which could be compensated for with various strategies already studied $[39,40]$. Once the start of the signal has been excluded, a moving window of 40 pixels is defined in the y direction. With the central line in the middle axis of the window, the symmetry for that axis is calculated, as shown in Figure 9b,c.

(a)

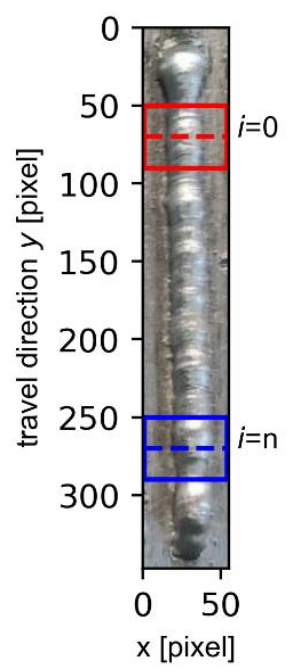

(b)

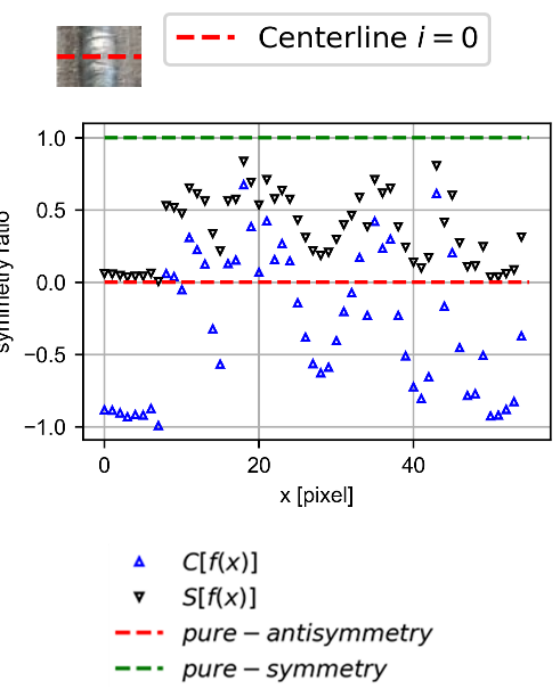

(c)
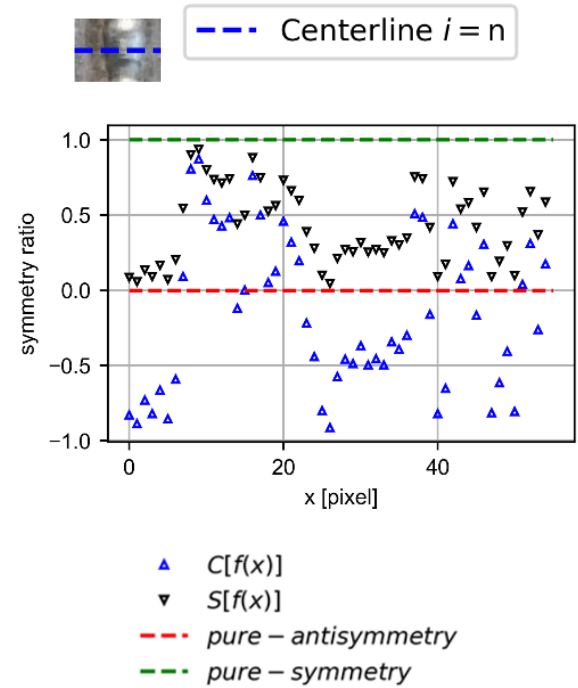

Figure 9. Image of the bead zero (a) in the plane xy, (b) the first window, and (c) the last window where symmetry is evaluated.

Once the symmetry in each of the windows is calculated, the evolution of the symmetry in the windows along the direction of advance of the torch can be observed in Figure 10. It is observed that in this case, test 2, the symmetry in the pulsed AC working mode is slightly higher than the symmetry in the pulsed GMAW bead. The beads produced with 
the pulsed strategies are better than those offered by the cold arc strategy. The projection of drops produced by the current pulse guarantees better welding in this deposition ratio.

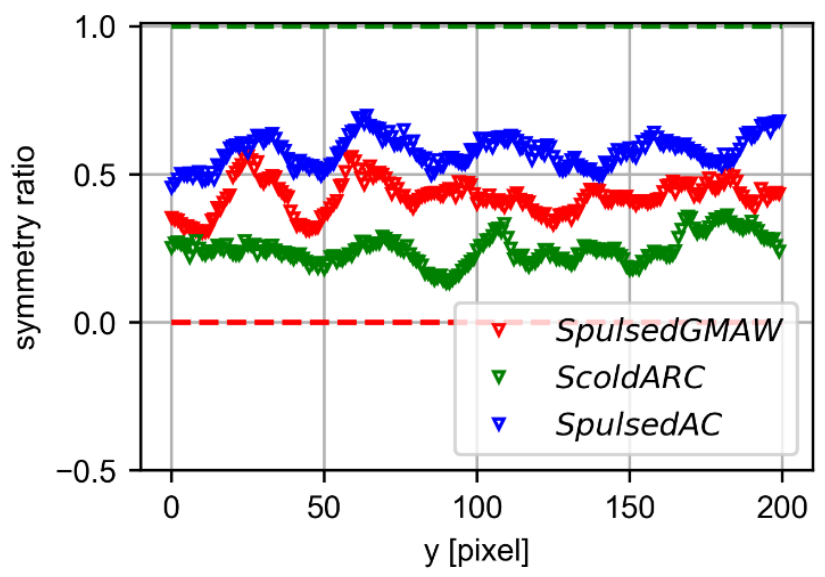

Figure 10. Symmetry ratio in test 2 for the different transfer modes.

Table 4 summarizes the results obtained in the mean symmetry of the entire bead in the y direction. Both pulsed AC and pulsed GMAW have better results than cold arc. It can also be seen how the increase in the deposition rate does not lead to a loss of symmetry in the bead. Even in the case of cold arc, low deposition rates are not recommended due to discontinuities in the process [41].

Table 4. Mono-layer weld beads surface appearance manufactured under three different working modes.

\begin{tabular}{|c|c|c|c|c|c|}
\hline \multirow[b]{2}{*}{ Test Run\# } & \multirow{2}{*}{$\begin{array}{c}\text { Wire Feed } \\
(\mathrm{m} / \mathrm{min})\end{array}$} & \multirow{2}{*}{$\begin{array}{l}\text { Traverse } \\
\text { Speed } \\
(\mathrm{cm} / \mathrm{min})\end{array}$} & \multicolumn{3}{|c|}{ Symmetry Ratio } \\
\hline & & & $\begin{array}{l}\text { Pulsed } \\
\text { GMAW }\end{array}$ & Cold Arc & Pulsed AC \\
\hline 1 & 4 & 100 & 0.49 & 0.1 & 0.61 \\
\hline 2 & 4 & 57 & 0.42 & 0.25 & 0.53 \\
\hline 3 & 4 & 33 & 0.43 & 0.3 & 0.22 \\
\hline 4 & 8 & 200 & 0.47 & 0.48 & 0.36 \\
\hline 5 & 8 & 114 & 0.61 & 0.48 & 0.57 \\
\hline 6 & 8 & 65 & 0.55 & 0.42 & 0.51 \\
\hline
\end{tabular}

\subsection{Zero Bead Symmetry Evaluation on the Transversal Axis}

The deposition conditions not ruled out in the study of the symmetry of the bead in the longitudinal direction were studied by analyzing the metallographic images under the microscope. Table 5 shows the set of analyzed images, following the method described in Sections 2.3 and 2.4. 
Table 5. Zero beads' transversal view under three different working modes [28].

\begin{tabular}{|c|c|c|c|c|c|c|}
\hline & $4 \mathrm{~m} / \mathrm{min}$ & $1 \mathrm{~mm}$ & & 8 & & $3 \mathrm{~mm}$ \\
\hline N\# & Pulsed GMAW & Pulsed AC & N\# & Pulsed GMAW & Cold Arc & Pulsed AC \\
\hline 1 & & & 4 & & & \\
\hline 2 & & & 5 & & & \\
\hline 3 & & - & 6 & & & \\
\hline
\end{tabular}

The porosity of aluminum alloy deposits using WAAM technology and traditional welding is mainly due to the presence of hydrogen in the process. A proportion of the hydrogen is encapsulated during the solidification process, creating porosities due to the difference between the solubility limits of hydrogen for aluminum in the solid or liquid state. Impurities and moisture that can often be found on the wire surface cause hydrogen to be present in the process. Other causes of porosity occurrence can be the angle of inclination of the torch and the purity of the shielding gas. The pulsed AC mode reduced the porosity levels of the deposited material, a key factor for the integrity and quality of the material. In the pulsed AC mode, when the current signal is negative it heats the previously deposited material, removing the oxide film created on the surface, and in this way, the hydrogen gas trapped in the material comes out, and consequently the porosity is reduced. This incidence substantially modifies the calculation of the symmetry of the image, therefore being of relevance.

After analyzing the images in Figure 11, the results of the total symmetry ratio, $S_{\text {Total }}$, of the image for the center of the bead is calculated as:

$$
S_{\text {Total }}=\frac{\sum_{i=0}^{n_{p z}} S[f(z)]}{n_{p z}}
$$

where $n_{p z}$ is the number of pixels of the image.

The symmetry in cold arc is greatly diminished by the high incidence of micropores which, being black dots in the grayscale image, are interpreted as a great source of antisymmetry. The results in pulsed transfer mode deposition images are higher in most cases. Symmetry also improves at high deposition rates. 


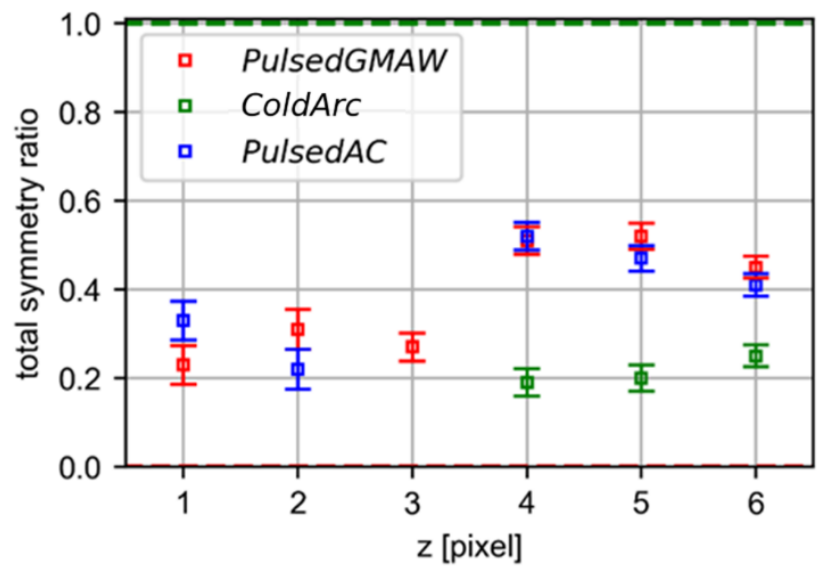

Figure 11. Results on symmetry for the comparison of the three different metal transfer modes.

\section{Discussion: Applicability Analysis}

This subsection analyzes the possible application of the methodology developed in this article in another case of additive manufacturing by WAAM. Figure 12a shows the longitudinal image of the beads for a case of WAAM in ER70 extracted from the literature [15]. For these images, we applied the formula proposed in Section 3.1. It is visually observed how in test 13 the bead presents an irregular outer surface despite being a fairly homogeneous bead in width. Once the initial and final sections of the chord were removed, the symmetry ratio along the forward direction y was obtained (Figure 12b).

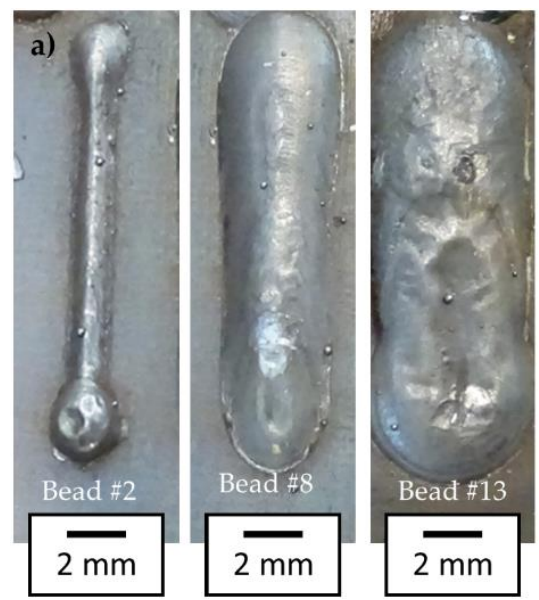

b)

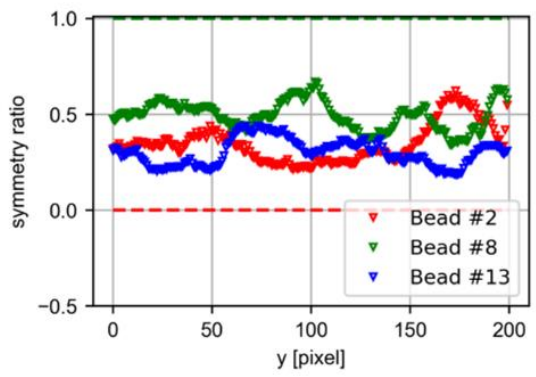

Figure 12. Mono-layer weld beads, (a) surface appearance manufactured and (b) symmetry ratio in ER70 steel under different welding conditions, extracted from Aldalur et al. [15].

Table 6 shows the welding parameters and bead geometry measurements taken from the paper [15]. The geometrical parameters average width $\left(w_{\text {avg }}\right)$ and average height of the bead $\left(h_{a v g}\right)$ were extracted from the analysis of the laser signal that reproduces the transverse geometry of the bead at different positions of the $y$-axis. In addition, this feature was selected because it defines a value of homogeneity and continuity of the weld. This geometrical feature (GF) value, calculated as the inverse, is the product of the inverse of the standard deviations of the height and width, following Equation (7):

$$
G F=\frac{\left(\frac{1}{\sigma_{w}} * \frac{1}{\sigma_{h}}\right)}{2}
$$


where,

$$
\sigma_{w}=\frac{\sqrt{\sum_{i=1}^{n}\left(w_{1}-\bar{w}\right)^{2}}}{n} \sigma_{h}=\frac{\sqrt{\sum_{i=1}^{n}\left(h_{i}-\bar{h}\right)^{2}}}{n}
$$

Table 6. Measurement results of the beads' geometry and total symmetry.

\begin{tabular}{ccccccc}
\hline $\begin{array}{c}\text { Beads } \\
\text { Number }\end{array}$ & $\begin{array}{c}\text { WFS } \\
(\mathbf{m} / \mathbf{m i n})\end{array}$ & $\begin{array}{c}\text { TS } \\
\mathbf{( c m / m i n )}\end{array}$ & $\mathbf{w}_{\text {avg }}(\mathbf{m m})$ & $\mathbf{h}_{\text {avg }}(\mathbf{m m})$ & GF & $\boldsymbol{S}_{\text {Total }}$ \\
\hline 2 & 4 & 65 & 4.62 & 1.69 & 49.45 & 0.35 \\
8 & 8 & 65 & 7.88 & 2.25 & 63.50 & 0.49 \\
13 & 12 & 30 & 17.21 & 4.19 & 6.86 & 0.25 \\
\hline
\end{tabular}

To the values presented in the literature and as an alternative to the GF, we have added the calculation of the total symmetry ratio in the longitudinal direction following the methodology defined in this paper. The values of the total symmetry ratio correlate with those previously published, thus, allowing us to establish a metric of the continuity and homogeneity of the zero bead. The main advantage of using the total symmetry ratio is its usability and lower implementation cost. The methodology based on image pro-cessing and the calculation of the total symmetry ratio requires only the integration of an industrial camera in the machine environment.

\section{Conclusions}

Image-based bead symmetry analysis yields interesting results, and in this case, it seems to be an interesting tool for comparing metal transfer modes. The conclusions obtained in this paper can be summarized in the following points:

- A methodology was developed for the analysis of the symmetry of the deposited zero beads through three transfer modes: pulsed GMAW, cold arc, and pulsed AC.

- Good quality beads were created with deposition ratios of $1.44 \mathrm{~kg} / \mathrm{h}$ of aluminum from the Al-5356 alloy.

- The symmetry analysis based on image processing indicates that the material deposited by pulsed methods has a better geometry than when cold arc is applied.

- In the longitudinal analysis of symmetry, it was observed that cold arc is not suitable for low deposition ratios, producing discontinuities in the bead.

- The study of symmetry in the transversal plane allows us not only to determine the goodness of the external form but also to be influenced by the existence of micropores. This causes the pulsed AC deposition method show the best symmetry results, with a value of 0.55 for a travel speed of $200 \mathrm{~cm} / \mathrm{min}$ and $8 \mathrm{~m} / \mathrm{min}$ of wire feed.

- The application of this methodology to other cases of both welding and additive manufacturing would allow establishing the goodness of the welding conditions based on the performance in image analysis of the zero beads. The application of the methodology to another case of additive manufacturing with ER70 steel material shows the usefulness of the work presented in this paper.

Regarding future lines derived from this paper, the following could be ruled out: (i) the possibility of extrapolating this analysis to welding processes and (ii) using signals from other non-destructive NDT sensors for online inspection of the deposition process.

Author Contributions: Conceptualization, F.V., A.S., and E.A.; Data curation, F.V., T.B., and E.A.; Formal analysis, F.V., T.B., and E.A.; Investigation, F.V., A.S., and E.A.; Methodology, F.V. and E.A.; Project administration, A.S; Supervision, A.S.; Validation, T.B., and A.S.; Writing-original draft, F.V., and T.B.; Writing-review and editing, F.V., T.B., A.S., and E.A. All authors have read and agreed to the published version of the manuscript.

Funding: The authors acknowledge the Basque Government for financing the HARIPLUS, HAZITEK 2019 program (ZL-2019/00352), and QUALYFAM project (kk-2020/00042). 
Institutional Review Board Statement: Not applicable.

Informed Consent Statement: Not applicable.

Data Availability Statement: Not applicable.

Conflicts of Interest: The authors declare no conflict of interest.

\section{References}

1. Rodrigues, T.A.; Duarte, V.; Miranda, R.M.; Santos, T.G.; Oliveira, J.P. Current Status and Perspectives on Wire and Arc Additive Manufacturing (WAAM). Materials 2019, 12, 1121. [CrossRef] [PubMed]

2. Baufeld, B.; Van der Biest, O.; Gault, R. Additive manufacturing of Ti-6Al-4V components by shaped metal deposition: Microstructure and mechanical properties. Mater. Des. 2010, 31 (Suppl. 1), S106-S111. [CrossRef]

3. Wu, B.; Pan, Z.; Ding, D.; Cuiuri, D.; Li, H.; Xu, J.; Norrish, J. A review of the wire arc additive manufacturing of metals: Properties, defects and quality improvement. J. Manuf. Process. 2018, 35, 127-139. [CrossRef]

4. Ding, D.; Pan, Z.; Cuiuri, D.; Li, H. Wire-feed additive manufacturing of metal components: Technologies, developments and future interests. Int. J. Adv. Manuf. Technol. 2015, 81, 465-481. [CrossRef]

5. Williams, S.W.; Martina, F.; Addison, A.C.; Ding, J.; Pardal, G.; Colegrove, P. Wire + Arc Additive Manufacturing. Mater. Sci. Technol. 2016, 32, 641-647. [CrossRef]

6. Tabernero, I.; Paskual, A.; Álvarez, P.; Suárez, A. Study on Arc Welding Processes for High Deposition Rate Additive Manufacturing. Procedia CIRP 2018, 68, 358-362.

7. Aldalur, E.; Veiga, F.; Suárez, A.; Bilbao, J.; Lamikiz, A. High deposition wire arc additive manufacturing of mild steel: Strategies and heat input effect on microstructure and mechanical properties. J. Manuf. Process. 2020, 58, 615-626. [CrossRef]

8. Américo, S.; Ponomarev, V.; Lucas, W. A scientific application oriented classification for metal transfer modes in GMA weld-ing. J. Mater. Process. Technol. 2012, 212, 1406-1413.

9. Zhai, P.; Xue, S.; Wang, J.; Tao, Y.; Chen, W.; Chen, T.; Ji, S. Comparative Study of Droplet Transfer Modes on Appearance, Microstructure, and Mechanical Properties of Weld during Pulsed GMAW. Metals 2020, 10, 611. [CrossRef]

10. Xia, C.; Pan, Z.; Polden, J.; Li, H.; Xu, Y.; Chen, S.; Zhang, Y. A review on wire arc additive manufacturing: Monitoring, control and a framework of automated system. J. Manuf. Syst. 2020, 57, 31-45. [CrossRef]

11. Ario Sunar, B. Monitoring of molten pool image during pipe welding in gas metal arc welding (GMAW) using machine vision. In Proceedings of the 2011 International Conference on Advanced Computer Science and Information Systems, Jakarta, Indonesia, 17-18 December 2011.

12. Pinto-Lopera, J.E.; Mauricio, J.; Motta, S.T.; Sadek, C.; Alfaro, A. Real-time measurement of width and height of weld beads in GMAW processes. Sensors 2016, 16, 1500. [CrossRef] [PubMed]

13. Xiong, J.; Guangjun, Z. Online measurement of bead geometry in GMAW-based additive manufacturing using passive vision. Meas. Sci. Technol. 2013, 24, 115103. [CrossRef]

14. Murray, P.E. Selecting parameters for GMAW using dimensional analysis. Weld. J. 2002, 81, 125-S.

15. Aldalur, E.; Veiga, F.; Suárez, A.; Bilbao, J.; Lamikiz, A. Analysis of the Wall Geometry with Different Strategies for High Deposition Wire Arc Additive Manufacturing of Mild Steel. Metals 2020, 10, 892. [CrossRef]

16. Kolahan, F.; Heidari, M. A new approach for predicting and optimizing weld bead geometry in GMAW. Int. J. Mech. Syst. Sci. Eng. 2010, 2, 138-142.

17. Xiong, J.; Zhang, G.; Hu, J.; Wu, L. Bead geometry prediction for robotic GMAW-based rapid manufacturing through a neural network and a second-order regression analysis. J. Intell. Manuf. 2014, 25, 157-163. [CrossRef]

18. Xiong, J.; Zhang, G.; Gao, H.; Wu, L. Modeling of bead section profile and overlapping beads with experimental validation for robotic GMAW-based rapid manufacturing. Robot. Comput. Integr. Manuf. 2013, 29, 417-423. [CrossRef]

19. Lorza, R.L.; García, R.E.; Martinez, R.F.; Calvo, M. Ángeles M. Using Genetic Algorithms with Multi-Objective Optimization to Adjust Finite Element Models of Welded Joints. Metals 2018, 8, 230. [CrossRef]

20. Ding, D.; He, F.; Yuan, L.; Pan, Z.; Wang, L.; Ros, M. The first step towards intelligent wire arc additive manufacturing: An automatic bead modelling system using machine learning through industrial information integration. J. Ind. Inf. Integr. 2021, 23, 100218. [CrossRef]

21. Karmuhilan, M.; Sood, A.K. Intelligent process model for bead geometry prediction in WAAM. Mater. Today Proc. 2018, 5, 24005-24013. [CrossRef]

22. Venkatarao, K. The use of teaching-learning based optimization technique for optimizing weld bead geometry as well as power consumption in additive manufacturing. J. Clean. Prod. 2021, 279, 123891. [CrossRef]

23. Dinovitzer, M.; Chen, X.; Laliberte, J.; Huang, X.; Frei, H. Effect of wire and arc additive manufacturing (WAAM) process parameters on bead geometry and microstructure. Addit. Manuf. 2019, 26, 138-146. [CrossRef]

24. Tang, S.; Guilan Wang, C.H.; Zhang, H. Investigation and control of weld bead ar both ends in WAAM. In Proceedings of the Solid Freeform Fab-rication 2019: Proceedings of the 30th Annual InternationalSolid Freeform Fabrication Symposium an Additive Manufacturing Conference, Austin, TX, USA, 12-14 August 2019.

25. Li, F.; Chen, S.; Shi, J.; Zhao, Y.; Tian, H. Thermoelectric Cooling-Aided Bead Geometry Regulation in Wire and Arc-Based Additive Manufacturing of Thin-Walled Structures. Appl. Sci. 2018, 8, 207. [CrossRef] 
26. Sarathchandra, D.; Davidson, M.J.; Visvanathan, G. Parameters effect on SS304 beads deposited by wire arc additive manufacturing. Mater. Manuf. Process. 2020, 35, 852-858. [CrossRef]

27. Wang, C.; Bai, H.; Ren, C.; Fang, X.; Lu, B. A Comprehensive Prediction Model of Bead Geometry in Wire and Arc Additive Manufacturing. J. Phys. Conf. Ser. 2020, 1624, 022018. [CrossRef]

28. Aldalur, E.; Suárez, A.; Veiga, F. Metal transfer modes for Wire Arc Additive Manufacturing Al-Mg alloys: Influence of heat input in microstructure and porosity. J. Mater. Process. Technol. 2021, 117271. [CrossRef]

29. Panchenko, O.; Kurushkin, D.; Mushnikov, I.; Khismatullin, A.; Popovich, A. A high-performance WAAM process for Al-Mg-Mn using controlled short-circuiting metal transfer at increased wire feed rate and increased travel speed. Mater. Des. 2020, 195, 109040. [CrossRef]

30. Zhu, L.; Luo, Y.; Han, J.; Zhang, C.; Xu, J.; Chengyang, Z. Energy characteristics of droplet transfer in wire-arc additive manufacturing based on the analysis of arc signals. Measurement 2019, 134, 804-813. [CrossRef]

31. Luo, Y.; Li, J.; Xu, J.; Zhu, L.; Han, J.; Zhang, C. Influence of pulsed arc on the metal droplet deposited by projected transfer mode in wire-arc additive manufacturing. J. Mater. Process. Technol. 2018, 259, 353-360. [CrossRef]

32. Shukla, P.; Dash, B.; Kiran, D.V.; Bukkapatnam, S. Arc Behavior in Wire Arc Additive Manufacturing Process. Procedia Manuf. 2020, 48, 725-729. [CrossRef]

33. Zhang, P.; Li, G.; Yan, H.; Tian, Y. Effect of positive/negative electrode ratio on cold metal transfer welding of 6061 aluminum alloy. Int. J. Adv. Manuf. Technol. 2019, 106, 1453-1464. [CrossRef]

34. Zhang, B.; Wang, C.; Wang, Z.; Zhang, L.; Gao, Q. Microstructure and properties of Al alloy ER5183 deposited by variable polarity cold metal transfer. J. Mater. Process. Technol. 2019, 267, 167-176. [CrossRef]

35. Cong, B.; Ding, J.; Williams, S. Effect of arc mode in cold metal transfer process on porosity of additively manufactured Al-6.3\%Cu alloy. Int. J. Adv. Manuf. Technol. 2015, 76, 1593-1606. [CrossRef]

36. Abo-Zahhad, M.; Gharieb, R.R.; Ahmed, S.M.; Donkol, A.A.E.-B. Edge Detection with a Preprocessing Approach. J. Signal Inf. Process. 2014, 5, 123-134. [CrossRef]

37. Zielke, T.; Brauckmann, M.; von Seelen, W. Intensity and edge-based symmetry detection applied to car-following. In European Conference on Computer Vision; Springer: Berlin/Heidelberg, Germany, 1992; pp. 865-873. [CrossRef]

38. Hu, Z.; Qin, X.; Shao, T.; Liu, H. Understanding and overcoming of abnormity at start and end of the weld bead in additive manufacturing with GMAW. Int. J. Adv. Manuf. Technol. 2018, 95, 2357-2368.

39. Bandari, Y.K.; Charrett, T.O.; Michel, F.; Ding, J.; Williams, S.W.; Tatam, R.P. Compensation strategies for robotic motion errors for additive manufacturing. In Proceedings of the 27th Annual International Solid Freeform Fabrication Symposium, Austin, TX, USA, 8-10 August 2016.

40. Kah, P.; Suoranta, R.; Martikainen, J. Advanced gas metal arc welding processes. Int. J. Adv. Manuf. Technol. 2012, 67, 655-674. [CrossRef]

41. Ryan, E.; Sabin, T.; Watts, J.; Whiting, M. The influence of build parameters and wire batch on porosity of wire and arc additive manufactured aluminium alloy 2319. J. Mater. Process. Technol. 2018, 262, 577-584. [CrossRef] 